\title{
Os dois circuitos da economia urbana no arranjo produtivo de confecções em Nova Friburgo-RJ
}

The two circuits of urban economy in productive arrangement of clothing in Nova Friburgo/RJ

Les deux circuits de l'économie urbaine de la production textile à Nova FriburgoRJ

Los dos circuitos de la economía urbana em la organización productiva de confección en Nova Friburgo-RJ

\section{Gabriel Amilton Bezerra Barros}

\section{(2) OpenEdition} Journals

Edição electrónica

URL: https://journals.openedition.org/espacoeconomia/21380

DOI: 10.4000/espacoeconomia. 21380

ISSN: 2317-7837

Editora

Núcleo de Pesquisa Espaço \& Economia

Refêrencia eletrónica

Gabriel Amilton Bezerra Barros, «Os dois circuitos da economia urbana no arranjo produtivo de confecções em Nova Friburgo-RJ», Espaço e Economia [Online], 22 | 2021, posto online no dia 15 janeiro 2022, consultado o 11 agosto 2022. URL: http://journals.openedition.org/espacoeconomia/ 21380 ; DOI: https://doi.org/10.4000/espacoeconomia.21380

Este documento foi criado de forma automática no dia 11 agosto 2022. 


\section{Os dois circuitos da economia urbana no arranjo produtivo de confecções em Nova Friburgo-RJ}

The two circuits of urban economy in productive arrangement of clothing in Nova Friburgo/RJ

Les deux circuits de l'économie urbaine de la production textile à Nova FriburgoRJ

Los dos circuitos de la economía urbana em la organización productiva de confección en Nova Friburgo-RJ

Gabriel Amilton Bezerra Barros

\section{Introdução}

Em O Espaço Dividido (2008 [1979]), Milton Santos propôs uma abordagem teórica baseada na existência de circuitos da economia urbana para se compreender o processo de industrialização e urbanização nos países subdesenvolvidos, também chamados países periféricos, de industrialização tardia. Embora forjada há algumas décadas, há certa contemporaneidade na teoria dos circuitos da economia urbana, desde que se considere alguns novos elementos, como a expansão de crédito entre os mais pobres e a popularização de tecnologias. Ademais, as transformações organizacionais decorrentes nas últimas décadas abriram a possibilidade para que formas de trabalho não modernas e, em sua maioria, precárias, fossem absorvidas na dinâmica de reprodução do capital, ainda que também se tenha induzido inovações gerenciais e produtivas (HARVEY, 1992). Essas transformações seguiram uma lógica que se aproveita de dinâmicas globais, dos avanços técnicos e da infraestrutura dos países centrais, da urbanização acelerada nos países periféricos e de seu crescimento desordenado, da mão de obra abundante e da terciarização da economia para uma produção e circulação integrada em diversas escalas. 
2 Como cada atividade tem um lugar para sua execução, o uso do espaço urbano difere de uma atividade para outra. Com o advento das cadeias globais de valor, cada etapa da produção passou a ser distribuída em espaços diferenciados. A configuração de cada lugar importa para o tipo de produção que ali se desenvolve e as características locais tendem a se fundir a características setoriais. Desse modo, indica-se uma necessidade de avaliação dos circuitos espaciais de produção por ramo de atividade (CATAIA; DA SILVA, 2013), que se acomodam de modos distintos nos espaços, explorando dali as características que lhe são favoráveis.

3 Algumas atividades evidenciam bem essa dinâmica, como o caso da indústria têxtil, que passou por transformações significativas nas últimas décadas. Seguindo a tendência à subcontratação, essa cadeia produtiva passou por uma reestruturação baseada em pequenas unidades produtivas, condizente com as transformações do mundo do trabalho em regime de acumulação flexível (HARVEY, 1992), e foi deslocada para países como Brasil, Bangladesh, China e Índia. A significativa participação dos países em desenvolvimento nessa indústria se dá, justamente, pelo uso intensivo de mão de obra, mais barata nesses espaços (GORINI, 2000).

4 São marcas da indústria de confecção atual, a fragmentação do processo fabril e o repasse da uma parte da produção para terceiros, permitindo um desmembramento do ciclo produtivo, isto é, a fragmentação das atividades. Essas atividades menores, como a montagem e acabamento das peças, podem ser realizadas em menores unidades produtivas - denominadas facções -, pequenas confecções, ateliês e nos domicílios. A descentralização, desverticalização e fragmentação da produção facilita a terceirização e a subcontratação, contribuindo para uma precarização do trabalho.

5 Aproximando o tema estudado a essas reflexões, parte dessa força de trabalho precarizada encontra abrigo no circuito inferior, mas ainda mantém vínculos com o circuito superior. Isso porque a pobreza e a desigualdade criam a necessidade de as pessoas desfavorecidas buscarem formas de acesso aos bens e serviços necessários à sobrevivência, que são os mesmos entre pobres e ricos, embora haja diferenças quantitativas e qualitativas no consumo, por isso dá-se a criação e manutenção dos dois circuitos.

6 É necessário destacar que o consumo de uma população não se prende ao circuito ao qual essa está vinculada, pelo contrário, o consumo em um circuito ou em outro tende a ser ocasional, de acordo com os bens e serviços que se procura. As classes médias e suas cestas de consumo evidenciam que se recorre a um ou outro circuito de maneira conveniente, usufruindo da modernidade do superior e beneficiando da espontaneidade do inferior. Do mesmo modo, o emprego da força de trabalho tipicamente ligada a um circuito pode ocorrer em outro, visto que frequentemente o circuito superior compra força de trabalho abrigada no circuito inferior. Assim sendo, uma atividade pode ter predominantemente características de um circuito e também apresentar algumas de outro, isso fica mais evidente em determinadas atividades (SANTOS, 2008), como o caso da indústria têxtil e de confecções.

7 Conjugados, o circuito superior se aproveita de situações e condições só encontradas em caráter de informalidade do circuito inferior para viabilizar a forma com que se dá a produção de artigos de vestuário em várias parte do mundo: concentradas em aglomerações produtivas especializadas onde predomina o trabalho mal remunerado e pouco qualificado (SCOTT, 2006). Ora, se os dois circuitos são resultados dos mesmos processos - a modernização tecnológica e seus impactos diferenciados sobre espaços e 
pessoas -, esses não podem ser isolados, suas dinâmicas se comunicam na forma da economia urbana dos países periféricos. Cada tipo de produção exige um determinado arranjo que garanta sua viabilidade, esse movimento exige transformar ou adaptar as condições às necessidades que são impostas. Na indústria de confecções, mesmo que a maior parte produtiva se dê significativamente no circuito inferior, algumas etapas do processo produtivo se desenvolvem no circuito superior, sobretudo as que dizem respeito à circulação da mercadoria em redes varejistas

8 Nesse sentido, a proposta desse artigo é analisar a indústria de confecção de Nova Friburgo, no estado do Rio de Janeiro, caracterizando-a como uma produção típica da economia urbana de países subdesenvolvidos pelo referencial teórico dos dois circuitos da economia urbana. Metodologicamente, trata-se de um estudo qualitativo que se utiliza de uma revisão bibliográfica centralizada na ideia seminal de Milton Santos e em trabalhos que investigaram o mesmo recorte espacial ou possuem proximidade temática. Também se utilizou como ferramentas o trabalho de campo, entrevistas com produtores, vendedores e consumidores, e coleta de dados em instituições locais, sindicatos patronal e laboral e prefeitura, como também dados de órgãos governamentais (RAIS/CAGED, IBGE). A partir do material bibliográfico diferenciou-se os dois circuitos da economia através de elementos teóricos, tendo estabelecido um contraponto a essa diferenciação a partir das observações em campo, o que permitiu um panorama geral que guiou também as entrevistas semiestruturadas e a elaboração de tabelas e quadros explicativos. A primeira parte do presente artigo apresenta a ideia central que dá origem ao referencial teórico que embasou nossas reflexões, seguida de uma segunda parte que relaciona a teoria dos circuitos a atividade produtiva têxtil e de confecções para, enfim, discutir como esse tema se relaciona na produção de moda íntima friburguense.

\section{Os dois circuitos da economia urbana}

O ponto de partida para compreender a teoria dos dois circuitos da economia urbana é que a ordem econômica mundial se define por uma relação de centro e periferia, com essa dependente daquele. Todavia, as ondas de modernização advindas dos epicentros tecnológicos são seletivas, atingindo apenas os espaços que lhes convém, ainda que seus impactos sejam generalizados. Dessa forma, cria-se contradições, combinações de forças antagônicas, ou, no caso dos dois circuitos, conjugação de dinâmicas modernas e dinâmicas arcaicas.

10 Países subdesenvolvidos, a periferia global, quando atingidos por essas ondas modernizadoras tendem a ter sua lógica local alterada, com novas dinâmicas e consequente nova organização espacial em função da nova estrutura de produção, seu impacto pode ser medido pela redução dos números de empregos.

Em Nova Friburgo, isso se refletiu significativamente através do processo de reestruturação produtiva que acarretou em uma série de demissões em decorrência da crise da indústria têxtil local, no último quarto do século XX. Através da aquisição de uma fábrica de tecidos, uma multinacional alemã ${ }^{1}$ se instalou na região e iniciou um processo de renovação de máquinas e atualização da produção, se encarregando de produzir desde a matéria-prima até o produto final, a lingerie. Em função disso, um volume considerável de trabalhadores foi demitido. Sem serem absorvidos pela 
indústria local, esses adquiriram ou receberam como parte da indenização antigas máquinas de costura e iniciaram pequenos empreendimentos e oficinas.

Embora o circuito superior tenda a controlar o mercado e dominar o espaço, devido à estrutura desigual característica dos espaços periféricos, algumas pessoas são excluídas ou precariamente inseridas na nova dinâmica, deixando uma organização residual, que é reclamada pelo circuito inferior. Dessa forma, criam-se contradições, combinações de forças antagônicas, ou, no caso dos dois circuitos, conjugação de dinâmicas modernas e dinâmicas arcaicas ${ }^{2}$.Os circuitos podem ser definidos pelas atividades realizadas em um determinado contexto e pelo setor da população que se vincula essencialmente a cada um (SANTOS, 2008, p. 42), sendo ambos os circuitos resultado da modernização tecnológica. Um deles comporta as atividades criadas pelas inovações e pelos progressos tecnológicos e as pessoas que deles se beneficiam. Em contrapartida, o outro comporta aqueles que se beneficiam parcialmente ou, até mesmo, não se beneficiam dos progressos técnicos recentes. É preciso, porém, fazer ressalvas sobre essa diferenciação, tendo em vista que as dinâmicas atuais acabam por mesclar e combinar características dos dois circuitos.

"Num complexo processo de produção de inovações tecnológicas e de produção de consumidores em todas as camadas sociais e lugares, poderíamos assinalar variáveis que ficam restritas à economia superior e outras que se banalizam. Para não perder o passo, as divisões sociais e territoriais do trabalho não hegemônicas precisam incorporar alguns elementos da modernidade" (SILVEIRA, 2015, p. 251).

Destaca-se, por exemplo, a expansão do crédito que alterou significativamente o consumo, principalmente das populações mais pobres. 0 cartão de crédito, embora não substitua o crédito informal concedido através da confiança, diminui os riscos do vendedor em não receber e permite que esse expanda seu mercado. O comprador também se beneficia, podendo arcar com as despesas da compra posteriormente e contribuindo para a expansão das finanças e de uma atividade cujo núcleo se localiza no circuito superior.

As diferenças que caracterizam os dois setores se encontram na ordem da tecnologia e de organização, principalmente, mas também de outras qualidades. As atividades do circuito superior são intensivas em capital - as indústrias e os serviços modernos - com acesso ao crédito formal e a serviços bancários e, por isso, são aquelas que usam técnicas modernas de produção e distribuição. O circuito inferior é intensivo em trabalho, dispõe de tecnologias arcaicas, possui maior dificuldade de acesso à crédito $\mathrm{e}$ movimenta um volume dinheiro líquido considerável para honrar suas obrigações (SANTOS, 2008).

15 As diferenças que caracterizam os dois setores se encontram na ordem da tecnologia e de organização, principalmente, mas também de outras qualidades, como discriminado na tabela 1. As atividades do circuito superior são intensivas em capital - as indústrias e os serviços modernos - com acesso ao crédito formal e a serviços bancários e, por isso, são aquelas que usam técnicas modernas de produção e distribuição. $O$ circuito inferior é intensivo em trabalho, dispõe de tecnologias arcaicas, possui maior dificuldade de acesso à crédito e movimenta um volume de dinheiro líquido considerável para honrar suas obrigações (SANTOS, 2008).

Uma vez que os dois circuitos se apresentam de forma bastante fluida para que forneçamos uma caracterização e diferenciação muito rígida, podemos nos apoiar na 
descrição da paisagem urbana para compreender como os dois circuitos se apresentam, como feito por Corrêa (2005). Assim, é possível observar

"modernos shopping centers que, muitas vezes, não estão distantes de um conjunto de biroscas; ruas onde convivem lojas departamentais, pertencentes às grandes organizações capitalistas, ou lojas especializadas em artigos de luxo, e vendedores ambulantes com sucedâneos baratos dos artigos vendidos nas lojas" (CORRÊA, 2005, p.75).

A formação dos dois circuitos também se dá devido à existência de um contingente de pessoas com salários baixos convivendo com pessoas com rendas mais elevadas. Apesar de ambos os grupos terem as mesmas necessidades, suas condições em satisfazê-las diferem. Como resultado das disparidades qualitativas e quantitativas do consumo, isto é, da própria desigualdade, tem-se a criação e manutenção de circuitos diferenciados de produção, distribuição e consumo voltados a atender as necessidades de cada grupo (SANTOS, 2008).

18 A formação dos dois circuitos também se dá devido à existência de um contingente de pessoas com salários baixos convivendo com pessoas com rendas mais elevadas. Apesar de ambos os grupos terem as mesmas necessidades, suas condições em satisfazê-las diferem. Como resultado das disparidades qualitativas e quantitativas do consumo, isto é, da própria desigualdade, tem-se a criação e manutenção de circuitos diferenciados de produção, distribuição e consumo voltados a atender as necessidades de cada grupo (SANTOS, 2008).

Deste modo, o emprego nos dois setores também possui diferenças significativas. A iniciar com a razão entre força de trabalho e unidades produtivas sendo maior no circuito superior. A média de ocupados por unidade de produção, no circuito inferior, é baixa, e ainda que esse circuito em números gerais seja o maior responsável pelo trabalho da população, a remuneração média é baixa, próxima ao limite do mínimo vital (SANTOS, 2008). Outra questão se refere à difícil tarefa de apreender a realidade do emprego no circuito inferior, que se apresenta frequentemente na forma de trabalho temporário, instável, irregular, aos níveis do subemprego e até mesmo desemprego.

No circuito inferior, as atividades e os agentes possuem formas particulares de organização e de trabalho. As necessidades ligadas à sobrevivência e a criação de oportunidades de geração de renda para uma multidão de trabalhadores pouco qualificados leva a adaptações constantes às condições conjunturais (TOZI; DUARTE; CASTANHEIRA, 2021, p.7)

Em contexto de flexibilização e desregulamentação das leis trabalhistas, o trabalho cada vez mais é inundado por precarização e informalidade. Outra questão é sobre o impacto dos smartphones e dos aplicativos nas relações de trabalho. Aplicativos de mensagens instantâneas podem aproximar compradores e vendedores. Condições de trabalhos podem ser negociadas rapidamente, contribuindo para que a subcontratação amplifique e se torne cada vez mais rarefeita. Há um mito de liberdade em empregar e ser empregado que, na realidade, não resiste ao fato que as negociações tendem a favorecer apenas aqueles que não estão a vender sua força de trabalho, contribuindo para a precarização do trabalho.

Por vezes, o circuito inferior se torna dependente do circuito superior pelos serviços prestados por atacadistas, transportadores, fornecedores de crédito. Pode-se até mesmo falar de um circuito superior marginal, que sobrevive graças aos empregos nãoqualificados e pequenos ofícios do circuito inferior. Seu consumo se dá de forma ampla, sobretudo as classes médias, mas ainda acessível para classes mais baixas e podendo ser 
requisitado pelas mais altas ou firmas, como no caso de serviços técnicos e de manutenção, através da contratação momentânea e direta. $O$ circuito superior também depende da produção em circuitos inferior, através de mecanismo de subcontratação. Atualmente, porém, não é incomum que atores do circuito inferior contrate serviços especializados como atividades de marketing, propaganda e serviços de consultoria. 0 circuito inferior também comercializa produtos que em diversos aspectos procuram copiar aqueles do circuito superior, ainda que detenha um potencial criativo elevado. Entretanto, o circuito superior possui grande vantagem por ser capaz de lançar tendências e criar gostos de mercado.

Até pela forma com que organiza e distribuição sua produção, o volume de bens comercializados por unidades no circuito superior é elevado, dessa forma, atacadistas e o comércio de exportação movimentam uma grande quantidade individual de mercadoria. No circuito inferior, o volume total de mercadorias até pode ser elevado, mas está distribuído por um número maior de unidades. Dessa forma, o curto prazo predomina no circuito inferior, pois há urgência em sobreviver e assegurar a vida cotidiana da família, enquanto no superior, as margens de lucro à médio prazo são mais viáveis, de forma que acumular capitais torna-se indispensável para a continuidade das atividades (SANTOS, 2008).

É preciso reconhecer o importante papel desempenhado pelos atacadistas, mas também pelos transportadores e atravessadores, como intermediadores entre os dois circuitos. A distribuição das mercadorias dos dois setores permite compreender que não se trata de um dualismo, mas de uma relação de coexistência e interdependência (XAVIER; CASTILLO, 2011). Agindo como um elo entre os dois circuitos, mas sobretudo, entre a produção e o consumo, os intermediadores são capazes de expandir territorialmente o consumo, atingido uma gama superior de estratos da sociedade.

Atualmente, o papel dos transportadores e atacadistas também se anuncia no aumento da interdependência dos lugares, ativada pela globalização. 0 aprofundamento das diferenças regionais, que permite a cada ramo da atividade escolher onde se localizar a partir dos benefícios providos pelas condições locais, também obriga as trocas interregionais. Se antes era possível que as atividades de um setor ficassem confinadas a um espaço pequeno, hoje isso é pouco praticado, o que se estende a atividades divididas entre os circuitos. Ainda que algumas produções tenham o circuito produtivo bastante globalizado, há atividades que dependem, por exemplo, de muita mão de obra, como a produção de artigos de vestuário e de mobiliário. Essas produções intensivas em determinado insumo ficam mais circunscritas a pontos do espaço que as oferecem em abundância, como as que resultam em aglomerações produtivas. Ademais, se o trabalho for fornecido em condições de subcontratação, é preciso uma certa estrutura que o permita assim ser.

Outras características fundamentais que diferenciam os dois circuitos são as escalas de articulação. $O$ circuito inferior é localmente articulado, enquanto o circuito superior depende de ações exógenas. Por vezes, o circuito superior depende de capital estrangeiro, investimentos distantes e ajuda governamental. $\mathrm{O}$ circuito inferior muitas vezes não consegue qualquer apoio nesse sentido, sendo até perseguido quando se trata de atividades informais (SANTOS, 2008). O circuito inferior mostrou-se bastante adaptativo à modernização e às transformações decorrentes. 0 computador, o celular, $a$ máquina de cartão de crédito, a internet, as redes sociais e outras inovações tornaramse ferramentas para aumentar a comercialização dos produtos, de modo que a 
publicidade e a ampliação do sistema de crédito induziram um aumento do consumo em todas as camadas sociais e, consequentemente, em ambos os circuitos. É claro que a expansão do acesso ao crédito às populações mais pobres também são mecanismos cruéis de endividamento, mas não deixa de ter papel fundamental no estímulo ao consumo nas classes mais baixas (CATAIA; DA SILVA, 2013). No contexto brasileiro, a Lei do Empreendedor Individual contribuiu para a promoção e formalização de microempreendedores, o que influencia na dinâmica dos circuitos.

Isso porque o circuito inferior foi confundido com o setor informal, pois é nesse circuito que se compreende a pequena produção manufatureira e artesanal e o comércio ambulante, combinados ao trabalho autônomo, o trabalho mal remunerado e trabalhado temporário ou instável e que passa pelo uso de mão de obra precarizada e não formalizada. Ademais, o que se refere como informal, nesse caso se deve àquilo que não se submete a regulação estatal, seja por necessidade ou por convicções ${ }^{3}$. É bem verdade que tal circuito envolva elevado grau de informalidade, mas, como já dito, não é essa a característica que o define. Reduzir o circuito inferior a informalidade é desconsiderar a diferença qualitativa e quantitativa de consumo e emprego que existe entre as diferentes classes. Mesmo em situação de formalidade, o emprego e o consumo podem estar abaixo ou próximo do mínimo vital. Ademais, se reduzirmos a questão à informalidade, o problema da desigualdade desaparece ou diminui de importância, pois é a própria desigualdade o elemento central da teoria dos dois circuitos, não qualquer outro aspecto. São as dinâmicas dos e entre os circuitos que os forma e nos permite discutir tal teoria a partir da sua efetiva contribuição.

\section{0 circuito inferior e superior de confecções}

27 A indústria têxtil ocupa um papel histórico, uma vez que se constitui como uma das atividades tradicionais que marcam a passagem da manufatura para a indústria, apontada como pioneira no processo de industrialização. Sua cadeia produtiva é caracterizada pela heterogeneidade, na existência desde grandes conglomerados multinacionais até pequenas empresas faccionistas, apresentando um mercado segmentado. Cada estágio da produção possui especificidades no que diz respeito aos níveis tecnológicos e qualificação de mão de obra, mas também sobre o tamanho das firmas, em uma estrutura que se destaca pela diluição do porte das empresas quanto mais ao fim do processo produtivo (HAGUENAUER et al., 2001). Sendo um dos setores mais difundidos espacialmente, o predomínio de pequenas e médias confecções ao fim do processo produtivo possibilita que a produção seja descentralizada e fragmentada, e que a força de trabalho seja subcontratada ou terceirizada.

As confecções possuem características ilustrativas sobre a produção e o consumo nos dois circuitos. 0 mercado é caracterizado pela diversificação de produtos, aberta a especialização e exploração de nichos diferenciados por qualidade e preço, no qual grandes e pequenas confecções desempenham papéis diferenciados. As grandes firmas são responsáveis sobretudo pela circulação e consumo das mercadorias em escala mundial, em grandes redes varejistas, butiques, feiras de moda, podendo se utilizar de revistas e magazines para divulgação de seus produtos. As confecções menores estão mais ligadas as circulação e consumo em escala local, dependem de redes alternativas em que o acesso ao mercado consumidor é intermediado por terceiros, logo, 
vendedores ambulantes e sacoleiros desempenham papel de semelhante importância para a pequena produção.

Tabela 1 - Agentes e etapas da produção de confecções nos circuitos da economia urbana

\begin{tabular}{|c|c|c|c|c|c|}
\hline Circuito & $\begin{array}{l}\text { Agentes que } \\
\text { comandam }\end{array}$ & Produção & Distribuição & Comércio & Consumo \\
\hline $\begin{array}{l}\text { Circuito } \\
\text { Superior }\end{array}$ & $\begin{array}{l}\text { Grandes } \\
\text { Marcas } \\
\text { Varejistas }\end{array}$ & 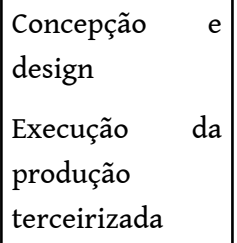 & $\begin{array}{l}\text { Executada por } \\
\text { empresas de } \\
\text { logística }\end{array}$ & $\begin{array}{l}\text { Pontos de vendas } \\
\text { próprios ou } \\
\text { autorizados } \\
\text { Comércio } \\
\text { Varejista }\end{array}$ & $\begin{array}{l}\text { Classe média e } \\
\text { consumidores } \\
\text { de todo } \\
\text { território } \\
\text { nacional }\end{array}$ \\
\hline $\begin{array}{l}\text { Circuito } \\
\text { Superior } \\
\text { Marginal }\end{array}$ & $\begin{array}{l}\text { Confecções de } \\
\text { Médio Porte }\end{array}$ & $\mid \begin{array}{ll}\text { Concepção } & \text { e } \\
\text { fabricação } & \\
\text { própria } & \text { ou } \\
\text { terceirizada } & \end{array}$ & $\begin{array}{l}\text { Próprios } \\
\text { produtores }\end{array}$ & $\begin{array}{l}\text { Comercialização } \\
\text { própria }\end{array}$ & Variado \\
\hline $\begin{array}{l}\text { Circuito } \\
\text { Inferior }\end{array}$ & $\begin{array}{l}\text { Vendedores } \\
\text { autônomos e } \\
\text { comércio de } \\
\text { pequena } \\
\text { dimensão }\end{array}$ & \begin{tabular}{|l|} 
Comerciantes \\
com fabricação \\
própria e/ou \\
produção \\
terceirizada
\end{tabular} & $\begin{array}{l}\text { Sacoleiros ou } \\
\text { realizadas } \\
\text { pelos próprios } \\
\text { produtores }\end{array}$ & $\begin{array}{lr}\text { Pontos de } & \text { vendas } \\
\text { em } & \text { bairros } \\
\text { comerciais } & \text { e } \\
\text { comércio } & \\
\text { doméstico } & \end{array}$ & $\begin{array}{l}\text { Amplo, de classe } \\
\text { baixa ou } \\
\text { consumidores } \\
\text { locais e } \\
\text { sacoleiros }\end{array}$ \\
\hline
\end{tabular}

Fonte: Adaptado de CATAIA; DA SILVA, 2013 com dados colhidos em pesquisa de campo.

É preciso entender que as relações entre pequenas e grandes firmas e suas ações são bastante complexas. Parte significativa da produção do circuito superior está vinculado - ou dependente - da produção no circuito inferior, condizente com as ideias de que os circuitos não podem ser isolados, formam um subsistema da economia urbana. A tendência a terceirizar a produção faz com que parte da produção de grandes marcas sejam executadas por facções, pequenas confecções e até mesmo, trabalhadores em domicílio.

A produção moderna na indústria têxtil apresenta uma íntima relação com o trabalho terceirizado (GORINI, 2000) e há algumas razões para a predominância da produção e do comércio informal nesse tipo de economia (SANTOS, 2008). A produção não apresenta grandes barreiras à entrada, pois é intensiva em trabalho e não exige grandes aportes de capital inicial. A mão de obra é desqualificada, abundante e barata, o que também tem relação com manutenção das taxas de desemprego e principalmente na existência do subemprego. A subcontratação e a possibilidade do trabalho em casa favorecem o trabalho familiar, sendo possível empregar mais pessoas sem mobilizar capital de giro, integrando familiares de acordo com a demanda, que por sua vez é flutuante. 0 comércio exige apenas uma pequena soma de dinheiro, a qual pode ser obtida através de crédito pessoal ou ainda através de consignação. Trabalha-se com estoque reduzido, sendo a capacidade de estocar regulada pela capacidade de vender, o que possibilita a renovação do estoque com certa facilidade.

Em decorrência das transformações organizacionais e técnicas, as grandes empresas se tornam cada vez menos empregadora, em razão disso teríamos um expressivo aumento 
do número de pequenas empresas, muitas vezes baseadas em relações parentais e familiares, essa expansão também é expansão do circuito inferior. Em consequência ao aumento de relações de emprego precárias e condições de subemprego, temos um processo intenso de precarização do trabalhador (MONTENEGRO, 2012; 2013). Disso se dá a formação do precariado, isto é, o proletariado precarizado que, em função da baixa qualificação, da falta de oportunidades de empregos, além da própria condição da pobreza, transitam da informalidade para a formalidade e apresentam uma taxa de rotatividade empregatícia elevada (BRAGA, 2012). Atividades industriais de baixa tecnologia e intensivas em mão de obra, como as de calçados, confecções e móveis tendem a se espacializar na forma de aglomerações produtivas ${ }^{4}$. Esses espaços tendem a ser bolsões de mão de obra barata, frequentemente voltados à exportação, mas com elevada capacidade de atração apresentam dinâmicas de produção e comercialização específicas (SCOTT, 2006), em nosso recorte espacial essas dinâmicas se estruturam sobre os dois circuitos da economia urbana.

\section{A indústria têxtil em Nova Friburgo}

Em Nova Friburgo, município da região serrana do estado do Rio de Janeiro, a indústria têxtil é a principal atividade econômica e a história aponta dois eventos chaves: a) a abertura das fábricas têxteis de capital estrangeiro Ypu e Arp, na década de 1920, dando origem a industrialização no município, enfim consolidada com a posterior chegada da fábrica Filó; e b) o desenvolvimento da indústria de pequeno porte, pela expansão da subcontratação e informalidade, com origem em uma reestruturação produtiva na década de 1970, resultando na falência de grandes fábricas e na liberação de um grande contingente de mão de obra qualificada.

A confecção de roupas íntimas era responsável, em 2019, por 13,7\% (7.031) dos empregos formais totais (51.289) do município de Nova Friburgo e $47 \%$ dos empregos formais da indústria de transformação (14.833), sendo 592 estabelecimentos voltados a atividade de confecção e 27 facções. No total, a indústria têxtil é responsável por 9.776 postos de trabalho e por mais de 21 mil empregos diretos e indiretos distribuídos em mais de 1.400 confecções e facções formais e informais, segundo dados do Sindicato das Indústrias do Vestuário de Nova Friburgo e Região (SindVest) e da prefeitura. Evidencia-se, com os dados apresentados na tabela 2, que o setor é o mais importante da economia local, tendo impacto estadual e nacional em número considerável de empregos e estabelecimento. Acrescente-se que sua organização e particularidades impactam diferentes dimensões da sociedade, extrapolando o aspecto econômico da vida local.

Tabela 2 - Estabelecimentos e Vínculos da Subclasse CNAE 2.0 Confecção de roupas íntimas em Nova Friburgo, Rio de Janeiro e Brasil em 2019

\begin{tabular}{|l|l|l|}
\hline & Estabelecimentos & Vínculos \\
\hline Nova Friburgo & 619 & 7.031 \\
\hline RJ & 894 & 15.031 \\
\hline
\end{tabular}




\begin{tabular}{|l|l|l|}
\hline Brasil & 4.687 & 69.862 \\
\hline
\end{tabular}

Fonte: Ministério do Trabalho, RAIS, 2020

34 A indústria têxtil se estabeleceu segundo os moldes da produção taylorista e foi marcada por um forte controle do trabalho e da vida social, mas, apesar das semelhanças, não se tratava de uma produção fordista. Com a crise econômica e a reestruturação ocorrida na década de 1980, tem-se como consequência da falência das grandes fábricas a atomização das unidades produtivas e a terceirização, com aumento do número de facções, que são unidades de produção cuja atividade se limita a uma etapa do processo de produção, geralmente costura e acabamento. As unidades faccionistas surgem da formação de pequenos negócios baseados em estruturas de relações familiares, de vizinhança e amizade, sem acesso ao crédito formal ou um elevado aporte de capital inicial (HASENCLEVER; MELO, 2000).

Sobre a questão da falta de capital no circuito inferior, Milton Santos (2008, p. 198) exemplifica que o elevado preço de uma máquina de costura para um alfaiate impõe a esse alugá-la e só adquirir uma nova caso seus negócios rendam frutos. Tal fato se assemelha ao acontecido no recorte espacial desse trabalho, onde boa parte das máquinas das primeiras gerações de costureiras autônomas fora alugada de um comerciante de tecidos (TEIXEIRA, 2004). Assim sendo, a maior parte da produção é de origem do trabalho familiar e autônomo, de baixa remuneração, realizado em domicílio, responsável pela maior parte da ocupação da população.

Em Nova Friburgo, constata-se três grupos de unidades produtivas:

Costureiras autônomas, facções e confecções informais de micro porte, com fornecedores e clientes situados localmente, geralmente subcontratadas e terceirizadas; Confecções formais de médio e pequeno porte, com interações regionais e mercado nacional, com loja própria e venda para redes varejistas e lojistas;

Confecções de marcas nacionais e internacionais voltada para o mercado externo;

Se atualmente a tendência das grandes marcas é descentralizar e terceirizar a produção, o começo da indústria têxtil na cidade foi concretizado em grandes galpões, sendo suas localizações de interessante consideração, como pode se observar no mapa 1. Distribuídas em três pontos distantes ao longo do Rio Bengalas, as três principais fábricas - Arp, Ypú e Filó - guiaram a urbanização da cidade e suas vilas operárias contribuíram respectivamente para a formação dos bairros de Olaria, Perissé e Lagoinha. 


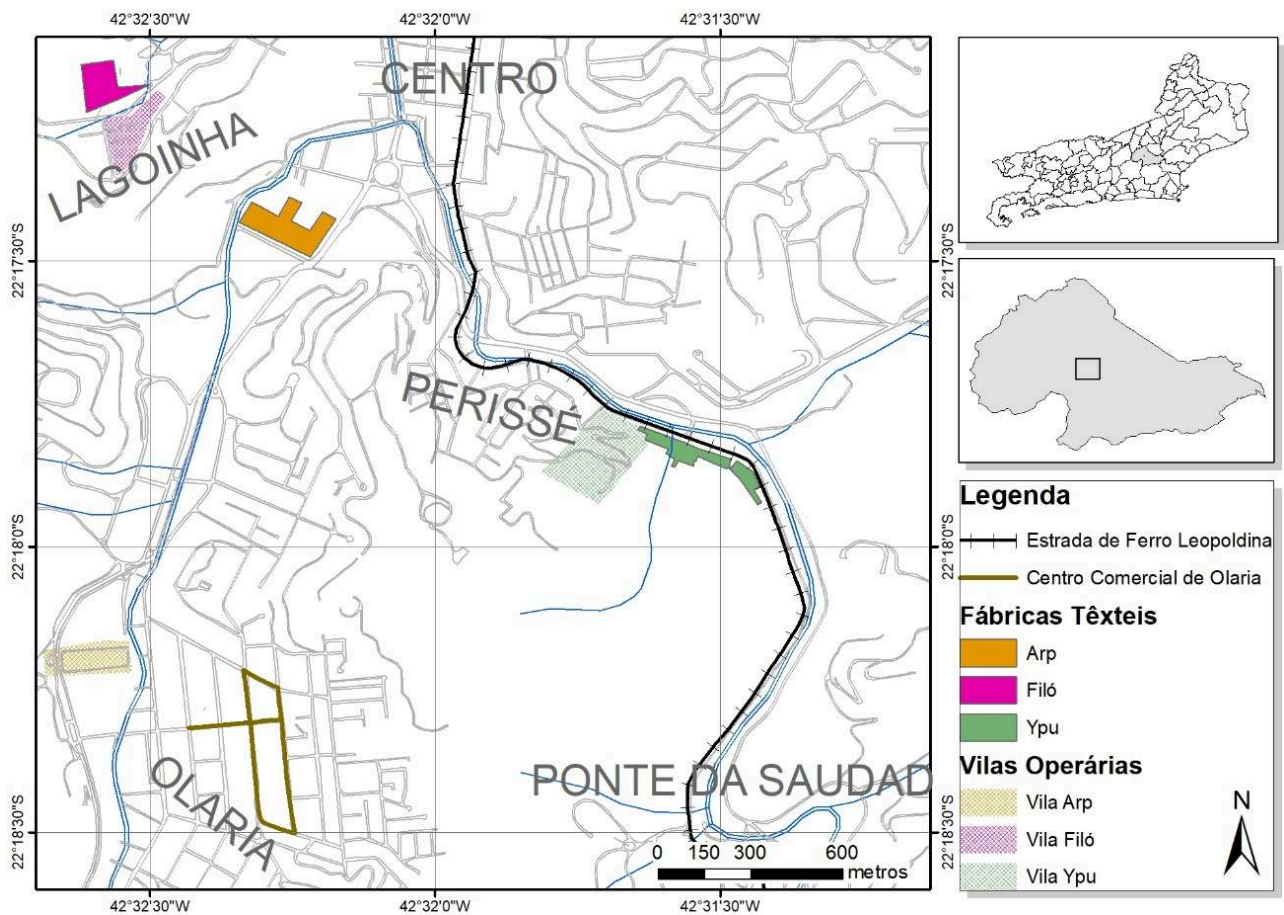

Fonte: Elaborado pelo autor

Olaria, um bairro de origem operária, aponta hoje como o principal espaço de produção e comércio de moda íntima, muito em razão do trabalho em domicílio integrar o cotidiano da família com o da produção, substituindo a tradição fabril de lógica taylorista e modificando a relação do trabalhador com o espaço, o tempo e do seu uso destes. O bairro em questão é onde se encontra a principal concentração de fábricas e lojas do ramo. Essa é uma característica relevante, pois há uma forte relação entre o capital industrial e o capital comercial na indústria têxtil, a ser explorada adiante.

A dinâmica de mercadoria é, principalmente, o que evidencia o entrelaçamento entre os dois circuitos, sendo também importante para compreender a importância da comercialização nesse tipo de produção. Devido ao capital limitado, necessita-se de um volume e frequência de venda elevados para que se reinvista o lucro no processo produtivo e aumente a renda, garantindo a viabilidade da atividade. Da necessidade de alto volume de produção vêm as longas jornadas de trabalho que obrigam as trabalhadoras a conciliar o trabalho com afazeres doméstico (CASTRO, 2011).

A produção em domicílio produz marcas significativas no espaço urbano. $O$ constante barulho das máquinas de costura, ao andar pelo bairro de Olaria, bem como a existência de lojas acopladas aos galpões de suas produções, sobrados que se dividem em casas, fábricas e lojas, evidenciam que a aglomeração urbana, a sincronicidade entre o trabalho doméstico e o trabalho fabril, são condições sociais de realização da indústria de confecção friburguense. Isso porque, embora seja comum apresentar o trabalho como familiar, é ao redor da figura feminina que se sustenta a produção domiciliar, o que denúncia, também "diferentes formas de exploração nessas relações: nos baixos níveis de renda e nas condições de trabalho e ser condicionado e condicionar as tarefas domésticas" (MATTOS, 2005, p. 194). 
44 A produção em domicílio é notável. A conciliação do trabalho fabril e do trabalho doméstico marcante no bairro de Olaria (MATTOS, 2011) na forma de "casas-fábricas" também pode ser observada em Conselheiro Paulino e, em uma tendência recente, se expande para áreas antes rurais. De modo geral, os locais de produção dividem-se em fábricas, galpões e domicílio. $\mathrm{O}$ ambiente fabril não é mais tão frequente em sua forma clássica, mas se transfere para lajes e ateliês, em formas de confecções de "fundo de quintal".

Essa produção tem como destino principal outras confecções, mas também são vendidas no comércio local, até mesmo informal, de baixa qualidade e de baixo custo, incluse na forma de casas-lojas. Em razão da variedade de produtores, têm-se uma variedade de produtos, não efetivamente porque são voltadas para nichos específicos, ainda que exista a produção voltada para mercados mais abastados, mas por não apresentarem um padrão.

Há uma estrutura comercial local que possibilita o escoamento da produção, extremamente fragmentada, e o alcance de uma produção bastante diferenciada a seus respectivos nichos. Os bairros de Olaria e Ponte da Saudade são os principais centros comerciais, com características bem distintas. $O$ primeiro é marcado pelo comércio atacado e atende sobretudo a sacoleiros. $O$ segundo tem uma dinâmica relacionada ao turismo, comércio a varejo, com o seu centro comercial localizado próximo a rodoviária, ao centro gastronômico e rodovias. Já foi notado por outros autores que pontualmente os circuitos podem criar áreas de influência diferenciadas, centros de ações simultâneas voltados a atender a população desses circuitos (CORRÊA, 2005).

47 A atividade informal e ambulante possibilita o comércio sem emissão de notas fiscais e o alcance a um mercado consumidor mais amplo que aumenta a capilaridade das mercadorias do pequeno produtor. A porcentagem quase total das lojas aceita cartão de crédito, o que possibilita um crédito rápido e prático para os sacoleiros e também aumenta a garantia do recebimento do pagamento. Lojas próprias e venda pela internet possibilitam a negociação de seus próprios produtos sem necessidade de investimento significativo em publicidade. Há, também, mecanismos que permitem o acesso a mercados maiores, mas que exigem maiores investimentos. Isso porque a participação em eventos e feiras impõe um padrão de qualidade para acompanhar tendências em modelagem e material e incorporar novas tecnologias cujo investimento apenas produtores com maior aporte financeiro são capazes de realizar.

A anual Feira de Moda Íntima, Praia, Fitness e Matéria-prima (FEVEST) tem o papel de promover as maiores marcas e também, de modo geral, a produção têxtil do município de Nova Friburgo e região. A feira atrai não apenas investidores e clientes, como também turistas, por realizar uma série de eventos, lançamento de tendências, desfiles e promoções, indiretamente desempenhando importante função publicitária ao promover a produção.

Parte da produção local é comercializada em shoppings e pontos de vendas em diversas regiões do Brasil. Marcas internacionais, como a Triumph, possuem produção local e podem ser encontradas em grandes redes varejistas, comércio internacional - $14 \%$ das confecções são exportadoras - e grandes plataformas de venda via internet. Garantindo a presença dos produtos em um número muito maior de pontos, aumenta-se a capilaridade da produção, o que a viabiliza. Não possuindo os mesmos recursos logísticos das grandes marcas e das redes varejistas, a abertura de loja própria no 
comércio local e a atuação de sacoleiras conseguem manter a capilaridade e a sobrevivência da produção no circuito inferior e do superior marginal.

Inclusive, o aparelho celular e a internet se popularizaram significativamente sobre todas as classes, embora tenha que ser contratado um plano de dados para acesso à rede, a maioria se comunica através dos aparelhos com fornecedores e clientes. Se tratando de internet, também vemos que a publicidade ganha espaço crescente em todas as atividades econômicas. Milton Santos apontou que a publicidade no circuito inferior era nula, porém a dinâmica atual torna a propaganda quase obrigatória para quase todo tipo de serviço e produto, até como um meio de conquistar mercado, principalmente considerando uma produção diversificada e com alta concorrência, como no caso da moda íntima de Nova Friburgo. Todas as confecções entrevistadas que possuem lojas próprias se utilizam de redes sociais para comercializar e apresentar produtos. Tendo, inclusive, lojas que só vendem exclusivamente no marketplace das redes sociais. Alguns revendedores e sacoleiros negociam diretamente com seus clientes através das redes sociais, criando perfis comerciais, realizando viagens periódicas ao polo produtivo de Nova Friburgo para abastecimento do estoque ou vendas por encomendas. Em vista do canal de distribuição usado pelas empresas, $44 \%$ daquelas em caráter formal e $23 \%$ das informais baseiam-se majoritariamente no comércio local. Das empresas informais, 45\% se utilizam de distribuidores, também chamados sacoleiros, como principal canal de escoamento da produção. Empresas formais também usufruem desse tipo de negócio, mas em porcentagem menor, por volta de 11\% (RANGEL; DE PAULA, 2012). o comércio dos produtos pelos sacoleiros é o que faz a ligação da produção do circuito inferior local com outros mercados. É a rede de comercialização o que permite tão elevado volume da produção, estimada pelo SEBRAE/RJ e o SindVest em um quarto da produção nacional, que apesar de fortemente localizada, possui uma distribuição descentralizada que assegura o consumo em circuitos inferiores de outras localidades.

51 A forte relação entre o capital industrial e o capital comercial na indústria têxtil se dá, ainda, na produção controlada por grandes marcas, com comercialização própria, e por redes varejistas, através de mercadorias encomendadas. Dessa forma, com relações pessoais e próximas, é comum que grandes e médias empresas, para complementar o volume de produção, subcontratem confecções menores, estabelecendo contratos informais por lotes de produtos e aplicando formas de controle de qualidade (DE LIMA, 2006).

Os circuitos da economia urbana servem à coesão dos processos sociais e econômicos São os circuitos que permitem alinhar produção, consumo, emprego, bens e serviços às parcelas da população de acordo com suas rendas. É por isso que alguns autores colocam o circuito inferior como aquele vinculado à sobrevivência, embora subordinados às lógicas do circuito superior (SILVEIRA, 2015). Não apontamos que o circuito inferior ainda sirva apenas à sobrevivência, mas que está vinculado às condições de vida da população de baixo poder aquisitivo que se integra socialmente através do consumo. Como agravante, o consumismo cria novas necessidades em ritmos acelerados e privilegiando parte da população que pode consumir frequentemente ou ocasionalmente (SANTOS, 2008). O cartão de crédito, que facilita o consumo incentivando o endividamento e transfere a poupança do circuito inferior para o superior, podendo ser considerado uma forma de espoliação, é aceito como forma de pagamento por todas as lojas do centro de Olaria. 
53 Se tratando o cartão de crédito também de uma inovação, temos um indicativo que os circuitos inferior e superior não podem mais ser diferenciados pelas modernizações. A modernização e os processos contemporâneos produção e consumo se dão de forma tão abundante e generalizada que é cada vez mais difícil que um dos circuitos se dê em seu estado puro. É preciso compreender que os dois circuitos estão em busca da "conquista do mercado e do domínio do espaço [...] representada pela tendência do circuito superior a unificar totalmente o mercado e o circuito inferior a reclamar uma parte na organização do espaço e a se colocar em concorrência com o circuito superior" (SANTOS, 2008, p. 359). Em Nova Friburgo, essa conquista do espaço se evidencia através da paisagem e das relações espaço-temporais.

Se o circuito inferior se perpetua no espaço urbano e para isso, buscam manter contato constante com os espaços produtivos (SANTOS, 2008), o bairro de Olaria representa significativamente isso. Embora atualmente, através do uso dos celulares e das redes sociais, o circuito inferior não é mais apenas localmente articulado, ele ainda depende da relação de proximidade. Essa proximidade se sustenta no cotidiano singular das casas-fábricas e do comércio popular, embora não seja informal. o circuito inferior também dependeria de relações diretas e personalizadas, as redes sociais permitem que compradores e vendedores estejam em contato e mantendo essa relação, sem que necessariamente estejam vivendo o mesmo cotidiano. Não é incomum perceber uma relação de amizade, com clientes não-locais perguntando pelos donos das lojas ou outros funcionários, evidenciando uma certa proximidade que permitem a eles negociar preços e descontos, uma marca do circuito inferior.

As relações pessoais são uma marca da produção de moda íntima friburguense, ela se estende desde a produção até a comercialização, como ilustramos. É nisso também que se sustenta a subcontratação. Dessa forma, com relações pessoais e próximas, é comum que grandes e médias empresas, para complementar o volume de produção, subcontratem confecções menores, estabelecendo contratos informais por lotes de produtos e aplicando formas de controle de qualidade (DE LIMA, 2006).

Um circuito pode se aproveitar do outro na formação de economias externas. Uma massa considerável de pessoas ofertando sua mão de obra por preços baixos é capaz de diminuir a taxa de remuneração. Nas aglomerações produtivas, como o caso Friburguense, essas dinâmicas são mais explícitas porque "existe um mercado de mão de obra, no qual é fácil empregar e despedir pessoas. Sob a barganha de superfície, entretanto, esse mercado revela uma complicada estrutura social" (BAGNASCO, 2001, p. 356).

57 Os dois circuitos da economia no caso das confecções friburguenses se evidenciam, portanto, na dinâmica do trabalho e do consumo. O trabalho predominante é o precarizado e mal remunerado, combinado a subcontratação, visando produções de baixo custo, enquanto o comércio se articula em escalas diferentes através do papel desempenhado por atores específicos, sacoleiros e redes varejistas. Coexistindo e até mesmo interagindo, empresas formais e informais, marcam a conjugação de estruturas que interligam o informal ao formal, o que evidencia a conjugação dos dois circuitos da economia urbana de Nova Friburgo. Coexistindo e até mesmo interagindo, empresas formais e informais, o moderno e o arcaico, atacado e varejo, assim como o trabalho em domicílio e o comércio por sacoleiras, marcam a conjugação de estruturas que interligam diferentes padrões de produção e consumo, o que evidencia a conjugação dos dois circuitos da economia urbana de Nova Friburgo. 


\section{Considerações Finais}

58 A teoria dos dois circuitos da economia urbana permite importante discussões sobre a forma com que se estrutura a economia política da urbanização periférica. Apesar das transformações econômicas e produtivas vivenciadas desde a sua concepção, ainda encontramos elementos dos dois circuitos na economia desses lugares, e, como aqui exposto, em Nova Friburgo. Os dois circuitos não funcionam de modo isolado, eles inclusive se complementam e assim o fazem através de uma dinâmica que interliga o cotidiano e o trabalho-consumo.

59 A confecção de roupas íntimas é a atividade mais importante da economia friburguense, responsável pela maior parte do número de empregos. As peças produzidas são distribuídas nacionalmente, inserindo variados tipos de produtores, comerciantes e clientes na dinâmica. Sobretudo através da subcontratação e terceirização, a articulação dos circuitos se dá na produção como também no comércio, com lojas próprias e vendas por atacado e varejo pelos próprios produtores, e na distribuição, através de sacoleiras e varejistas. A atividade não tem apenas importância em si mesma, visto que também movimenta o turismo, o comércio local e outras atividades relacionadas.

60 A existência de pequenos negócios (formais e informais) e de um polo produtivo já estruturado aponta que a organização da produção e da economia local nos moldes aqui discutidos é capaz de absorver um volume considerável de trabalhadores, frequentemente precarizados e explorados. A compreensão da economia local através de sua atividade principal passa por compreender suas estruturas, destacando o circuito inferior como importante abrigo para parte da população e integrado ao circuito superior, que permite o funcionamento com certo grau de eficiência da atividade, embora assentada em dinâmicas com algum grau de perversidade. Evidenciase, assim, que os circuitos não se trata apenas de condições diferentes de produção, consumo e distribuição, mas por uma articulação complexa que permeia o cotidiano e se sustenta em uma subordinação do circuito inferior e, principalmente, da sua população frente às dinâmicas ditadas pelo circuito superior. $O$ circuito inferior, em Nova Friburgo e em qualquer outro recorte espacial, é evidência que essas dinâmicas perpetuam a pobreza urbana disfarçadas de resiliência.

\section{BIBLIOGRAFIA}

BAGNASCO, Arnaldo. A teoria do desenvolvimento e o caso italiano. In: Arbix, G.; Zilbovícius, M.; Abramovay, R. (Orgs.). Razões e ficções do desenvolvimento. São Paulo: Editora Unesp/Edusp, 2001.

BRAGA, Ruy. Das ideologias do progresso técnico à crise da sociedade do trabalho. Revista Novos Rumos, n. 26, 2012. 
BRASIL. Ministério do Trabalho e Emprego. Programa de Disseminação das Estatísticas do Trabalho. Relação Anual de Informações Sociais (RAIS) Brasília, DF, 2020.

CASTRO, Rômulo. Resistência e Colaboração na reestruturação produtiva: uma análise das operárias costureiras em Nova Friburgo/RJ. (Dissertação) Mestrado em Ciências Sociais, Universidade Estadual Paulista, Marília, 2011.

CATAIA, Márcio; DA SILVA, Silvana Cristina. Considerações sobre a teoria dos dois circuitos da economia urbana na atualidade. Boletim Campineiro de Geografia, v. 3, n. 1, p. 55-75, 2013.

CORRÊA, Roberto Lobato. Trajetórias geográficas. 3ª edição. Rio de Janeiro: Bertrand Brasil, 1997. DE LIMA, Fabiana. O Sistema Produtivo Local de Moda Íntima de Nova Friburgo: reflexões sobre o novo paradigma do desenvolvimento local. 2006. Tese de Doutorado. UNIVERSIDADE FEDERAL DO RIO DE JANEIRO.

GORINI, Ana Paula. Panorama do setor têxtil no Brasil e no mundo: reestruturação e perspectivas. 2000.

HAGUENAUER, Lia et al. Evolução das cadeias produtivas brasileiras na década de 90. 2001.

HARVEY, David. Condição Pós-Moderna: uma pesquisa sobre as origens da mudança cultural. São Paulo, Ed. Loyola, 1992.

HASENCLEVER, Lia; MELO, Luiz Carlos. Estudo do pólo têxtil e de confecções de Nova Friburgo. Rio de Janeiro: UFRJ, 2000.

MATTOS, Regina. Desvendando o íntimo espaço da moda. Tese (Doutorado em Geografia), Universidade Federal Fluminense, Niterói, 2005.

MATTOS, Regina. Arranjos produtivos locais no interior fluminense: o polo de moda íntima de Nova Friburgo e região. Geopuc, revista do Departamento de Geografia da PUC-Rio, v. 4, n. 7, 2011.

MONTENEGRO, Marina Regitz. A teoria dos circuitos da economia urbana de Milton Santos: de seu surgimento à sua atualização. Revista Geográfica Venezolana, v. 53, n. 1, p. 147-164, 2012.

MONTENEGRO, Marina Regitz. Dinamismos atuais do circuito inferior da economia urbana na cidade de São Paulo: expansão e renovação. GEOUSP Espaço e Tempo (Online), v. 17, n. 2, p. 33-45, 2013.

RANGEL, Fernanda; DE PAULA, Teófilo. Arranjo produtivo local de moda íntima de Nova Friburgo - RJ: perfil atual e perspectivas de desenvolvimento. Ciências Humanas e Sociais em Revista, v. 34, p. 10-30, 2012.

SANTOS, Milton. O espaço dividido: os dois circuitos da economia urbana dos países subdesenvolvidos; tradução Myrna T. Rego Viana. $2^{\mathrm{a}}$ Edição. São Paulo: EdUSP, 2008

SANTOS, Milton. A natureza do espaço: espaço e tempo: razão e emoção. $3^{a}$ edição. São Paulo: Editora da Universidade de São Paulo, 2000.

SCOTT, Allen. The Changing Global Geography of Low-Technology, Labor Intensive Industry: Clothing, Footwear, and Furniture. World Development, v. 34, n. 9, p. 1517-1536, set. 2006.

SILVEIRA, María Laura. Modernização contemporânea e nova constituição dos circuitos da economia urbana. GEOUSP Espaço e Tempo (Online), v. 19, n. 2, p. 245-261, 2015.

TEIXEIRA, Renato. A Formação do Pólo de Confecções de Nova Friburgo. Dissertação (Mestrado em Economia), Universidade Federal Fluminense, Niterói, 2004. 
TOZI, Fábio; DUARTE, Leandro Ribeiro; CASTANHEIRA, Gabriel Rocha. Trabalho precário, espaço precário: as plataformas digitais de transporte e os circuitos da economia urbana no Brasil.

Ar@cne, v. 25, 2021

XAVIER, Marcos; CASTILLO, Ricardo. A reprodução do atacado distribuidor como um elo entre os dois circuitos da economia urbana no Brasil. GEOUSP Espaço e Tempo (Online), n. 29, p. 3-17, 2011.

\section{NOTAS}

1. Em 1968, a Triumph Internacional adquiriu a Fábrica de Filó, fundada em 1925.

2. Em abordagens anteriores, os próprios circuitos foram chamados de circuito moderno e circuito tradicional, de tal modo, também não convém assim defini-los tanto quanto se referir a eles como formal e informal, pois não é isso que lhe caracterizam.

3. A informalidade embora seja uma indução do desemprego, pode ter outras razões, como aqueles que não querem se submeter ao pagamento de impostos, seja porque isso significaria menores taxas de ganhos e lucro ou por compreenderem impostos como algo negativo.

4. No Brasil são diversos os exemplos de aglomerações dessa natureza: os APLs Calçadistas de Birigui/SP, Franca/SP e Jaú/SP; de Confecções em Maringá/PR, Caruaru/PE e Nova Friburgo/RJ; e Moveleiros de Ubá/MG, Bento Gonçalvez/RS, entre outros.

\section{RESUMOS}

A teorização da economia urbana pelos dois circuitos, quando proposta, permitiu uma nova abordagem para compreender a urbanização e a organização do espaço geográfico dos países periféricos, se mantendo atual obstante as transformações do capitalismo contemporâneo. Todavia, pela revalorização dos lugares, faz-se necessário uma discussão localizada e setorizada desta teoria. Esse artigo objetiva, através de uma pesquisa bibliográfica e investigação de campo, realizar uma breve reavaliação da teoria dos circuitos da economia urbana visando compreender como esses se fazem presente na estrutura econômica de Nova Friburgo abordada a partir da indústria têxtil. A indústria de confecção local possui uma estrutura produtiva e distributiva que possibilita a atividade ser viável, empregando quantidade considerável de mão de obra e criando um sistema que se concretiza no espaço urbano, principalmente pela produção em domicílio. Tal indústria também mobiliza e cria estruturas que conjugam os dois circuitos, resultando em uma dinâmica própria.

The theory of two circuits of the urban economy, when proposed, allowed a new approach to understand urbanization and organization in periphery countries, remaining actual despite the transformations of contemporary capitalism. However, due the revaluation of space, a localized and sectorized discussion becomes more appropriate. This paper aims, through bibliographic research and field study, to carry out a brief reevaluation of the theory of the two circuits of urban economy to understand how they are present in the economic structure from textile industry of Nova Friburgo. The local textile and clothing industry has a productive and distributive structure that allows the activity to be viable, employing a substancial amount of 
labor and creating a system that takes place in the urban space, mainly with home production. Such an industry also mobilizes and creates structures that combine the two circuits, resulting in a particular dynamic.

La théorie des deux circuits de l'économie urbaine, proposée par Milton Santos dans les années 1970, a permis une nouvelle approche sur l'urbanisation et l'organisation des pays périphériques, restant actuelle malgré les transformations du capitalisme contemporain. Cependant, en raison de la réévaluation de l'espace, une discussion plus locale et sectorielle devient plus appropriée. Cet article vise à effectuer une brève réévaluation de la théorie des deux circuits de l'économie urbaine pour essayer de comprendre comment ils sont présents dans la structure économique de l'industrie textile de Nova Friburgo. L'industrie locale du textile et de l'habillement a une structure productive et distributive qui la rend viable, employant une quantité considérable de main-d'œuvre et créant un système qui se déroule principalement avec la production domestique dans l'espace urbain. Une telle industrie est responsable si de mobiliser que de créer structures qui combinent les deux circuits, aboutissant à une dynamique particulière.

La teorización de la economía urbana por los dos circuitos, cuando se propuso, permitió un nuevo enfoque para entender la urbanización y la organización del espacio geográfico de los países periféricos, manteniéndose atual a pesar de las transformaciones del capitalismo contemporáneo. Sin embargo, debido a la revalorización del lugar, una discusión localizada y sectorizada de esta teoria se vuelve más apropiada. Este artículo tiene como objetivo, a través de la investigación bibliográfica y de campo, realizar una breve reevaluación de la teoría de los circuitos de la economía urbana en un intento por comprender cómo estos están presentes en la estructura económica de Nova Friburgo abordada desde la industria textil. La industria local textil y de la confección tiene una estructura productiva y distributiva que permite que la actividad sea viable, empleando una cantidad considerable de mano de obra y creando un sistema que se desarrolla en el espacio urbano, principalmente atraves de la producción doméstica. Esta industria también moviliza y crea estructuras que combinan los dos circuitos, lo que resulta en una dinámica particular.

\section{ÍNDICE}

Keywords: urban economy circuits; productive agglomeration; informal economy Mots-clés: circuits d'économie urbaine; agglomération productive; économie informelle ; industrie textile; Nova Friburgo-RJ

Palabras claves: circuitos de economía urbana; aglomeración productiva; economía informal; industria textil; Nova Friburgo-RJ

Palavras-chave: circuitos da economia urbana; aglomeração produtiva; economia informal; indústria têxtil; Nova Friburgo-RJ

\section{AUTOR}

\section{GABRIEL AMILTON BEZERRA BARROS}

Mestrando em Geografia pela Universidade Federal Fluminense. Email: gabrielamiltonbarros@id.uff.br 